\title{
The Teaching Reform Guided by the Basic Conception of Engineering Education Professional Certification
}

\author{
Zhang Yuping \\ School of Measurement and Control Technology and \\ Communications Engineering \\ Harbin University of Science and Technology \\ Harbin, China
}

\author{
Li Chen \\ School of Electrical Engineering and Automation \\ Harbin Institute of Technology \\ Harbin, China
}

\begin{abstract}
Engineering education professional certification abides by three basic concepts: achievement orientation, studentcentered, continuous improvement. It focuses on the cultivation of the students' ability. This will guide the teaching to transform from the imparting knowledge type to cultivating ability type. To reform the teaching of "Network Application Technology" course, based on the basic concepts of engineering education professional certification. The reform contents include teaching concept, teaching mode, teaching content, teaching method and examination mechanism. To grasp the basic principles of engineering education that it must face the engineering practice. To comprehensive train the ability of students use their knowledge to solve practical engineering problems. The results of practice show that the teaching reform has the promoting effect to cultivate the students' learning initiative, the further exploration and enquiry mind for the problem and the attitude and consciousness for the pursuit of innovation. It accords with the basic conception of engineering education professional certification.
\end{abstract}

Keywords-engineering education professional certification; teaching reform; ability orientation; "Network Application Technology" course

\section{INTRODUCTION}

In recent years, the higher engineering education in China has great development, basic meet the needs of the domestic economic and social development, the scale has reached the world's largest[1]. Improve the quality of education has become the primary task of the higher engineering education. Professional certification is an important part of higher education evaluation system, is the important ways and means for guaranteeing and improving the quality of education. Engineering education professional certification has been attached great importance from more and more countries in the world[2]. In June 2013, our country joined the "Washington Agreement", and has been a member of the signing the agreement. It marks the curtain of engineering education professional certification which has internationally essence equivalent has opened in our country. The core of "Washington Agreement" is the members of the signatories acknowledge the profession certified meets the academic requirements of engineering practice, has substantial equivalence. This will provide a good platform for our country's higher education go to the world, service to the world, merge into the world[3 6].

Engineering education professional certification abides by three basic concepts: achievement orientation, studentcentered, continuous improvement. These ideas are very important to guide and promote the professional construction and teaching reform, to guarantee and improve the quality of engineering education personnel training[7].

"Network Application Technology" is a compulsory course for the measurement and control technology and instrument specialty undergraduate, students are required to familiarize with electronic technology, measurement and control circuit, automatic control theory, sensor technology, microcomputer principle and single-chip microcomputer technology, under the premise of being familiar with the pre-project basic theory course, learn the new professional theoretical knowledge such as the basic knowledge of data communication, measurement and control system networking technology, Fieldbus technology and the communication network commonly used by measurement and control system. Course covers a wide range of knowledge and requires the students' ability to use knowledge comprehensively is higher. It has strong practicality and applicability, at the same time, the technology and method adopted has been developing rapidly with the progress of the industry.

Under the big background of engineering education professional certification, the teaching of "Network Application Technology" course continue to use the traditional form and the method can't meet the demand of engineering education professional certification standards. Therefore, in order to effectively support professional certification, and to achieve the goal of students' ability upgrade, in engineering education professional certification three basic idea as the guidance, in view of the teaching idea, teaching mode, teaching content, teaching methods and assessment mechanism, etc. for the corresponding reform is imperative. 


\section{The MAin Content OF TEACHING REFORM}

The core idea of engineering education professional certification is achievement orientation, student-centered, continuous improvement. The concept of engineering education accreditation based on the achievement orientation and China's traditional engineering education concept based on course orientation have essential difference. The Chinese traditional education emphasizes to preach, knowledge and solutions. Its core is a teacher how to teach well. On the school-running mechanism, close the door, lack interaction with the industry and the social. In the curriculum provision, emphasizing the unity, less consider the needs of industry and students. In the evaluation system, emphasis on theoretical study and test scores, the lack of practical ability examination, lack of the evaluation of industry.

Engineering education accreditation is mainly emphasize the cultivation of students ability, such as self-study ability, analysis and solving problem ability, active learning ability, practice ability, team work ability, communication ability, etc., the core is the students how to learn it well. This requirement of ability oriented guide teaching from knowledge type to ability type.

\section{A. The Transformation of Teaching Philosophy}

China's engineering education professional certification standards have a total of seven indicators, in turn, is the student, training goal, graduation requirements, continuous improvement, the course system, teaching staff and support conditions. The set of these indicators fully embodies the philosophy of student-centered: student is the primary indicator, other indicators are set for the students meet graduation requirements, and then training goal can be achieved.

Teaching design, teaching process and teaching evaluation should be centered on students. Grasp the basic principles of engineering education must face the engineering practice, comprehensive guide students to cultivate the ability to use knowledge to solve practical engineering problems, the correct understanding the engineering influences to the objective world and the society. The requirements for the students of the teachers more focus on cultivating students' learning initiative, the further exploration and enquiry mind for the problem and the attitude and consciousness for the pursuit of innovation[8]. It puts forward higher request, on the teachers themselves in the knowledge structure, education teaching skills, teaching and management art etc., to update their education ideas continuously, advancing with the times.

\section{B. The Change of Teaching Model}

Our traditional teaching emphasizes the common training, ignore the personality development. Under the imprisoned of "three unified" (unified teaching plans, unified teaching outline, unified teaching material) the classroom teaching becomes a standard "package", no matter how big or small appetite, taste is light or heavy, each a fill in his stomach[7]. Too much emphasis on common training, has neglected the student personality development, is not conducive to cultivate students' innovation consciousness and creative ability. The basic conception of engineering education professional certification lead teaching mode transform towards studentcentered.

Student-centered teaching mode emphasizes the subject status of students in teaching. For this, the research teaching mode has been designed. All the teaching content can be divided into three modules: basic knowledge of network and data communication, the network communication technology is commonly used in measurement and control system, networking advanced control system. The teaching mode of each teaching module is shown in figure 1.

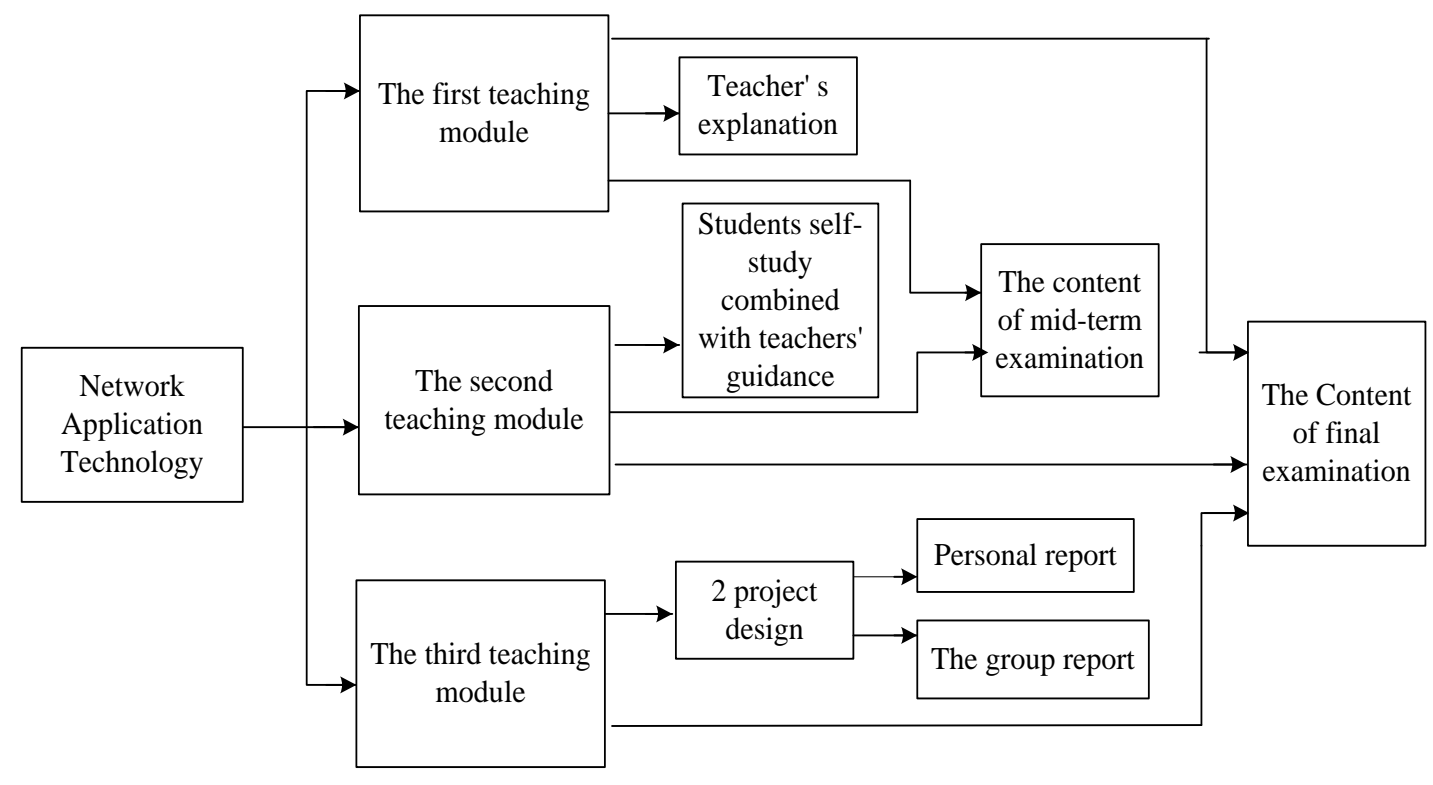

Fig.1. Schematic diagram of teaching modes 
According to the characteristics of the various modules adopt different teaching mode respectively. The first module is basic knowledge of network and data communication, has the characteristics of strong theoretical property and more basic concepts, use of class teaching mode. The second module is network communication technology commonly used in measurement and control system, has the characteristics of large amount of information and strong applicability, by adopting the combination teaching modes of self-study and guidance for teachers, guides the student to read widely relevant material, make the students which have strong selfstudy ability can further strengthen on the depth and breadth of knowledge. The third module is networking advanced control system, has the characteristics of strong comprehensive and strong practicality, by adopting the teaching mode of project design and form personal and group report, teachers guide students through the Internet and library to consult a large number of references, and to know the domestic and foreign research present situation of the design project, find out the method to solve the problem, design a reasonable solution. Group report is formed through team discussion, and be reported with the PPT form by a representative of the group. The results of group report are given after the classmate mutual evaluation and teacher evaluation. About personal achievement, according to the personal contribution to ranking, the ranking order is different and the weight is different. The result of group report multiplied by the weight of someone is equal to someone's achievement. This way can arouse the enthusiasm of students' active learning, also can cultivate the students' team consciousness.

In the teaching process always put students in the "center", fully embodies the teaching concept of "students-oriented". The role of teachers and students has a big change, teachers are no longer the owner, initiator and controller of knowledge, but the participants, guide and facilitator of the teaching process. Students are no longer the passive recipients of knowledge, but active learners, independent construction discoverer, positive and persistent explorer.

\section{The Reform and Optimization of Teaching Content}

The content of courses should be oriented towards the target of the Measurement and Control Technology and Instrument specification engineering education certification, to train the high quality personnel that would be recognized by the industry. Meanwhile, it should highlight the professional feature of the college and academic discipline, closely follow the development of society and meet the requirement of relative industries and fields. Upon this principle, keep the essentials of existing content of courses and remove those no in conformity with the Certification.

Combined with the research of his own, Professors should adjust in the course the content of the introduction of new materials, process, technology and equipment which reflects the current status and trends of the specialty, to make the course an integration of classic, basic, practical and advanced content. It will inspire the learning interests of student by appropriately fading the sophisticated theory in the courses and strengthening the application and practice. To make students deeply understand the theory and method of networking measurement and control system design, it is necessary to incorporate more experiments in the course, and to create more opportunities for students to work by their own hands in the laboratory.

\section{The Innovation of Teaching Methods}

To meet the requirement of engineering education professional certification, teachers will have to keep the teaching methods updated and innovated to improve the quality of teaching. The teaching methods can be designed to aim at a practical project, to train the students to enhance the capability of learning and team work by a way of case analysis, integrated design, group study, special training and etc. This will also improve the capability of design and consciousness of the engineering of the students. Teachers should deeply research the current situation of engineering education in both domestic and overseas, and teach the student the most advanced science ideology and outcomes in the world[9]. In teaching process, teachers should make use of multimedia resources effectively to make the knowledge visualized to stimulate the learning interests, so that the students study more positively.

To train the capability of independent analysis and thinking of the students, teachers should rise questions in the class and arrange assignment, and then encourage students to think and discuss by group. Teachers will make summary and give comment on the results presented by students to make them be involved positively. Arrangement of seminar and workshop is necessary to encourage students to discuss specific topics based on the key and difficult points in the course. The way of discussion of assignment could be flexible, so that students will think actively and increase their consciousness of innovation.

\section{E. Diversification of Examination and Evaluation Mechanism}

To inspect the effectiveness of the teaching, making examination and evaluation is necessary. It is clearly required by the engineering education certification index that the scholastic achievement of all the students is an important indicator of the Certification. It also required that an effective assessment system of student achievement should be established. In the system, the supporting relationship between courses and graduation requirement should be built, and then the various weight coefficients will be given based on the supporting strength. The weight coefficient will be used as the target value of assessment, the sum of all the weight coefficients should be 1 . This can convert the concept of Graduation Requirements into accountable index points, and then realize the index point one by one by allocating them into the teaching activities. This makes it possible to make assessment and records of the teaching activities and outcomes for each item. By enabling Graduation Requirements to correspondent to each teaching course and the quality of each teaching step, an effective assessment system of achievement and capability of students is built.

To apply the assessment of capability of students based on result-oriented into the examination and evaluation mechanism of the course, and by combining the mechanism 
with the existing normal mechanism of check-in, class work, and the performance of the final examination, it will contribute to enhance the learning initiatives of students and their consciousness and attitude of innovation.

Considering the features of "Networking Application Technology" course, take the following assessment mode:

$$
T=O+M+F
$$

In above formula, $\mathrm{T}=$ Total score, $\mathrm{O}=$ ordinary assessment, $\mathrm{M}=$ midterm examination, $\mathrm{F}=$ final examination.

Among them, the ordinary assessment includes Attendance, Practice Assessment (self-study report and group discussion report), teacher's evaluation and the experiment evaluation. Practice Assessment (self-study report and group discussion report), teacher's evaluation and the experiment evaluation.

By doing comprehensive assessment of students' attendance, discussion in class and class work, teachers are able to make assessment emphatically of the study attitude, discipline and students' subjective initiatives and etc. The assessment of practice will be done by combining the teaching of experiment and topic designs, by this way, the evaluation of students' creative thinking and capability as well as practical ability can be completed.

Midterm examination will focus on the assessment of basic knowledge and theories that learnt by students, while the final examination will increase the weighing of questions of subjectivity and applications. By means of the diversified development of the assessment system, the learning progress can be reflected completely and precisely. For the purpose of examining the engineering application ability of the student basing on the examination contents at various stages, designing multiple examination models is good for the improvement of the comprehensive quality of the students.

The first stage is close-book examination. The questions are mainly in single forms and with some comprehensives. The selection of questions will aim at the assessment of the understanding of basic knowledge and theory by students. The second stage examination is the combination of the reports of self-study and workshop, this examination is designed to evaluate the students' capability of comprehensive analysis and problem solving. This stage is of great importance to encourage the students to study initiatively and positively. The third stage is the final close-book examination. The question types are different from that of the first stage, and mainly are comprehensive questions, to guide students to associate the theories they have learnt with the practice. The purpose of this stage examination is to evaluate the capability of engineering application of the students.

\section{CONCLUSION}

Under the guidance of the basic concept of engineering education professional certification, the innovation of the course of "Networking Application Technology" has been conducted in the respects of Teaching Philosophy, Teaching Model, Teaching Content, Teaching Method and Examination and Evaluation Mechanism. Through the practice in the four classes in the year of 2013-2014 and 2014-2015, the innovation had been proved to have positive roles in promoting the ability of students' engineering application. It meets the requirement of the basic concept of engineering education professional certification.

\section{REFERENCES}

[1] Wu Qidi, "Reform and development of engineering education in our country”. China's Higher Education Evaluation, 2007(4), pp.3-7. (In Chinese)

[2] Li Liangjun, Yan Xingchun, Yi Shuping, Chen Bingkui, "Under the background of engineering education professional certification analysis and measurement of graduates basic requirements". Higher Education of Construction, 2013, 22 (4), pp.27 32. (In Chinese)

[3] Shao Hui, Ge Xuikun, Bi Haipu, "The guide of Engineering education certification in the specialty construction and reform thinking”. Journal of Changzhou university (Social Science edition). Vol. 15. No 1 Jan. 2014, pp.104 107. (In Chinese)

[4] Lou Jianming, Bao Xudi, Fu Yueqian, "For engineering education professional certification to strengthen the construction of engineering training cente”. Research and exploration of laboratory, 2013,32(11), pp.340-343. (In Chinese)

[5] Zhang Wenxue, Liu Junxia, Peng Jing, "The building of engineering education professional certification system and its potential impact on the higher engineering education”. Tsinghua Journal of Education, 2007 (6), pp. 60-63. (In Chinese)

[6] Chen Wensong, "Engineering education professional certification and its influence on the higher engineering education”. Higher Education BBS, 2011 (7), pp.29-31. (In Chinese)

[7] Li Zhiyi, "Analytical the student-centered concept of engineering education professional certification”. Education and Teaching, 2014 (21) pp. $19 \sim 22$. (In Chinese)

[8] Wan Linlin, Wu Qiaoping, Deng Chaohui, “The course reform of machinery manufacture equipment design under engineering education professional certification". The contemporary education theory and practice, Vol. 7 No. 4 Apr. 2015, pp.40 42. (In Chinese)

[9] Du Xiaodong, Li Heqin, Zhang Xuebin, “The teaching reform thinking of engineering material course adapt to the engineering education professional certification standards”. College Education, 2014 (2), pp.117 118. (In Chinese) 